\title{
Industry Institute Interaction for Outcome Based Education
}

\author{
P S Gowra ${ }^{1}$, Rajeshwari Hegde ${ }^{2}$ \\ ${ }^{1,2}$ Department of Electronics \& Telecommunication \\ Engineering, BMS College of Engineering, Bangalore \\ ${ }^{1}$ gowra.tce@bmsce.ac.in \\ ${ }^{2}$ rajeshwari.hegde@gmail.com
}

\begin{abstract}
The traditional or input based education is teacher centric, where in a teacher always tries to complete the syllabus on time, not concerning about whether the students have understood the subject. The faculty will evaluate the students based on their performance in the tests and examinations. The adoption of Outcome Based Education $(\mathrm{OBE})$ has changed the entire teaching learning process. The education is no longer teacher centric. The OBE requires students to demonstrate their skills rather than scoring marks. Since the key generators of innovations are the technical institutions and the implementers are the industries, there is a need for the industry institute interaction through the Memorandum of Understanding (MoU). In this paper, the OBE adopted in the department of Telecommunication Engineering, BMS College of Engineering (BMSCE), Bangalore which is an autonomous institute under Visvesvaraya Technological University, Belguam, India through industry institute interaction is presented. The objective of this paper is to demonstrate the impact of industry institute interaction in achieving Outcome Based Education. There was a significant improvement in the attainment of higher POs through this interaction.
\end{abstract}

Keywords: CIE. Course Outcome (CO), Course End Survey (CES), OBE, Program Outcome (PO), Semester End Examination (SEE).

\section{Introduction}

Traditional education is a learning process where students and teachers are physically present in the same place and at the same time. The traditional way of conveying information is the chalk and talk method. It involves placing a standard well-defined set of resources at the students' disposal, and evaluating them against set criteria through relative grades and ranking.

\section{Corresponding Author}

Rajeshwari Hegde, Dept. of ETE, BMSCE

rajeshwari.hegde@gmail.com

Graduates however are often not completely prepared to work in the industry due to lack of practical knowledge, communication skills, interpersonal skills, analytical skills, time management, attitude etc [1].
In view of improving the performance of the students, universities are moving towards adopting Outcome Based Education (OBE) where there is always a provision for continuous quality improvement. Graduates will be more relevant to industry as they are well prepared by acquiring the required skills to face many challenges. It would be a win-win situation for both industry and academia [2].

The engineering education system today faces the challenge of having to constantly react and adapt to keep up with rapid advancement in technology. This involves continuously updating curricula by introducing new courses, upgrading laboratory facilities by introducing modern tools, and training faculty to handle new courses to cope with the challenges to be faced in industry. This will enhance the confidence of graduates to work in any industry as individuals, decision makers, team leaders etc.

For industries to survive in this competitive world, they must adopt latest technology and provide world class service which needs skilled engineers. Academic institutions will be able to provide skilled engineers by training their students on current and future technologies with the help of industries. Hence it is absolutely essential that academic institutions and industries work together for their mutual benefit as well as for society.

There are many ways of establishing collaborations between academia and the industry. Memorandums of Understanding (MoU) with various industries provide a platform for students to exhibit their skills by participating in national level competitions, working on industry relevant projects, presenting their work at reputed conferences and publishing it in journals. Similarly, using industry input in designing curricula and creating a culture of outcomeoriented research are other ways to establish strong collaborative networks between academic institutes and the industry.

The paper is organized as follows. Section 2 deals with the need for industry-academia collaboration, and briefly outlines a few ways of achieving this collaboration. Section 3 deals with using MoUs to achieve this goal. Section 4 elaborates on the role of industries in curriculum design. Section 5 deals with how industries can help create a wider culture of outcome-based research. Section 6 deals with case studies of interaction with industries. Section 7 deals with interaction with industries to promote ethical and spiritual values. The paper is concluded in section 8 .

2. Industry-Academia Collaboration: Why and how? 
Today, we need innovation in all walks of life. Since the key generators of innovation are technical institutions and the implementers are industries, there is a need for industry-institute interaction. There are many benefits to be gained by both parties as a consequence of such an interaction.

Academic institutions must be capable of producing industry-ready engineers, who are able to understand and tackle current technological challenges without excessive guidance. While classroom teaching goes a long way towards fulfilling this objective, it is essential to collaborate with the industry to complement technical education learnt in the classroom. This is due to many reasons:

- Constantly evolving technology takes time to translate to courses taught in university, and collaboration with industry hastens this process.

- Academic institutions are generally focussed on publications rather than the development of innovative products and patents. Using research carried out by students as part of their academic work to produce an innovative product with the help of industry experts would align the incentives of both parties.

- Finally, an interaction with industries is a requirement for the accomplishment of Outcome Based Education (OBE).

Similarly, the industry has a need to constantly adapt its human resources and their technical skills to the changing technical needs of society. Undertaking this exercise with fresh graduates from scratch can be expensive, inefficient and time-consuming. Collaborations with academic institutions can be beneficial in this regard:

- As noted above, industry experts can benefit from the work done by students on research projects and utilize it to create innovative products, thereby saving them time and money.

- In addition, collaborations with academic institutions will help them identify talented engineers for their companies, who can then be trained very early on (through internships, projects, etc.) to integrate into their line of work.

- Conducting competitions and project contests for students could also result in the publication of papers and creation of patents for the companies, thereby making them thought-leaders in their respective fields.

However, collaboration with industry for academic activities is a challenging task as it involves many detailed discussions with industry partners about the role played by both the parties and the outcomes of the collaboration. There are many ways through which academic institutes can collaborate and interact with the industry. These include through Memorandums of Understanding (MoUs), involving industries in curriculum design and increasing their input in designing research. We elaborate on these in the following sections.

\section{Memorandums of Understanding (MoUs)}

MoUs between the industry and academia will strengthen the relationship between academia and industry and help the academic institute to produce industry-ready engineers. The list of activities carried out by the students of BMSCE with the help of industry experts are listed below.

1. Internship for students.

2. Faculty development programs.

3. Research and Development Projects.

4. Industrial visits.

5. Training students in association with industry.

6. Working model competitions.

7. Technical paper presentation.

8. Workshop, Seminars by Industry

9. Joint publications and patents [3]

The traditional way of approaching the industry for the MoU is shown in fig. 1 .

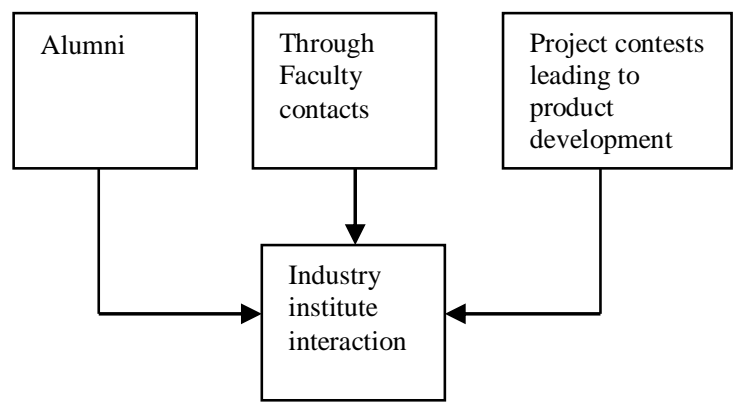

Fig.1 Traditional mode of interaction

Many academic institutions try to interact with the industry through alumni working in the industry, faculty contact with the industry, procurement of equipment, software \& hardware tools for the department/institution and innovative projects carried out by students in industries leading to publications, product development etc. Alumni play a major role in establishing the relationship with the industry by delivering invited lectures and guiding the students for their academic projects.

The sustainment of MoU is another challenging issue since the technology changes very fast. Once the MoU is done, the institution must invest for the sustainability of the MoU for long terms, by procuring new tools and upgrading the current tools provided by the industry as part of the MoU.

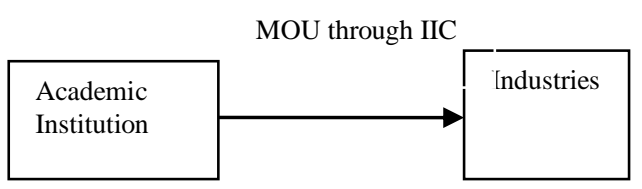

Fig.2: Modern mode of interaction

More recently, academic institutes are standardizing these interactions with the industry and establishing dedicated groups to facilitate increased collaborations. For example, the Industry Interaction Council (IIC) established in BMSCE facilitates the exchange of ideas amongst students, faculty and the industry. The main objective of this cell is to strengthen the relationship between the institute and industry resulting in a mutually beneficial partnership. This 
cell would play a major role in collaborating with industrial organizations to work on various research problems of mutual interest by entering into MoUs which would facilitate the activities listed previously in this section.

To work collaboratively with industries for the sustainable growth of both industry and institution, the Department of Electronics and Telecommunication Engineering (ETE) at BMSCE has been interacting with Reliance Jio, Stellapps Technologies and CB Institute of NW Technologies for active involvement in the partial delivery of courses, industry visits, internships and placements. The department also had MoUs with Texas Instruments (TI) and ZTE India Pvt Ltd. (ZTE).

\section{Role of industries in curriculum design}

In addition to establishing close relationships between the industry and technical institutions through MoUs, there is a need to introduce industry-oriented courses into the curriculum of engineering education to meet the industry's needs [4]. With a growing need to think out of the box, curriculum design must comprise of well-distinguished facets of engineering education.

Industry-oriented courses help students acquire basic knowledge and skills of various fields in the industry and understand their significance. It also helps students to think creatively and provide practical solutions for the societal needs, as most courses designed by the industry are practical-oriented.

At the Department of ETE, BMSCE, industries played a major role in setting up the curricula in the domains of Embedded Systems, Analog Electronic Circuits, Analog \& Digital Communication, Electronic Measurements, Wireless Communication, Verilog and VHDL and Sustainable Telecommunication Networks. The curriculum design with the help of industry experts has helped students to learn about modern tools and technology.

The MoU with Texas Instruments has resulted in the introduction of a new elective course titled "Low Power Microcontroller-MSP430". Students could develop the prototypes of the embedded systems in line with market demand and societal needs. A project titled "Minimal usage of Water Resource for Car Washing using Autonomous Robot" carried out using the hardware and software provided by Texas Instruments received consolation prize of Rs 10,000 in the National Level Design contest organized by TI. Many students got an opportunity to undertake internships in the domain of their interest which in turn helped them to get placed in companies such as Nokia Seimens, Robert Bosch, Texas Instruments etc. The students could also perform well in competitive exams.

\section{Knowledge and infrastructure sharing to foster a culture of outcome-based/practical research}

A culture of research among students and faculty provides a supportive environment in which extensive literature survey, problem identification, methodology of implementation, tools required and the outcomes of the research work are involved. As such, the development of research culture among students require experts from both industry and academia to set clear research goals and problem statements. This is facilitated through talks and seminars by industry experts, leading to in-depth discussions on challenges facing the industry and how they can be solved [5].

In addition, the set research goals must be accompanied by ample resources for the accomplishment of the same. The infrastructure provided by the industries have helped undergraduate students to carry out the research work in their field of interest which has led to several publications in reputed journals and conferences. This has also resulted in a prototype model developed by our students to meet societal needs. One such prototype is for the navigational assistance for the visually impaired. The other prototype was a low cost and low power solution for traffic violation.

\section{Case studies of Interaction and MoUs with Industries}

In this section, the outcomes of interactions with various industries at the departmental as well as institutional level are presented.

\section{A. Reliance JIO}

The interaction with Reliance Jio started with an invited talk on Wireless Communication Trends under IEEEBMSCE student chapter in the year 2018, which covered topics like how frequencies are used and how merging of various companies are profitable to the society. The talk also dealt with $5 \mathrm{G}$ technology and its features. Fig. 3 shows the first interaction with the industry expert from Jio.

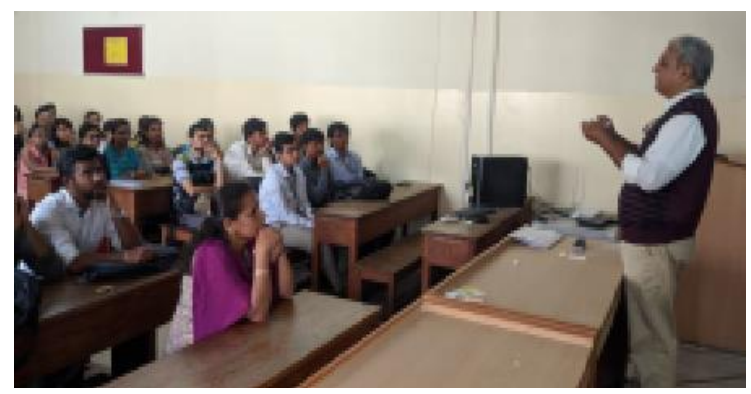

Fig 3: Interaction with industry expert from JIO

Consequently, to further capitalise on the technical knowledge of the industry expert in the field of telecommunication, the department invited him to deliver an industry-oriented course on "Sustainable Telecommunication Networks" which was a 2-credit core course introduced for $8^{\text {th }}$ semester. The course curriculum was designed keeping full-fledged focus on OBE and the defined COs are given below.

- C01: Ability to understand and explain the need for sustainability, role of regulatory bodies, radiation hazards and revenue models for telecommunication networks.

- CO2: Ability to apply knowledge of radiation hazards to minimize the effect on human health and environment. 
- CO3: Ability to apply knowledge of finance management to arrive at effective revenue models for telecommunication networks.

- CO4: Ability to engage in independent learning, submit a report and use ICT for effective presentation on the study of topics related to awareness on Mobile Tower Radiation \& Its Impacts on Environment, human health and protection from radiation hazards.

This 2-credit course covers two lecture sessions per week and a total of 24 lecture sessions in the semester. Students are assessed by conducting two internals (CIE) and a selfstudy component. Each CIE would be conducted with 40 as the maximum marks and the self-study would be evaluated with 20 as the maximum marks and later it would be reduced to 10 marks. The final weightage for all the internal assessments put together stood at 50 (40 marks for the CIE tests, 10 marks for the self-study component). The SEE would have a weightage of 50 marks taking the overall course assessment against a maximum of 100 Marks.

The course delivery was well structured to prepare them for industries as well as for higher education. The self-study component involved technical paper writing and presentation by students on topics to address CO4. This aspect also addressed Program Outcomes (POs) PO6 and PO7 (POs listed further below). As a part of self-study, a class of 60 students were given many challenging issues to discuss and debate to arrive at the topic for the paper writing. A team of 3-4 students was formed and the topic was finalized after the discussion and debate. The rubrics for self-study component as part of the course is shown in Table 1.

Table I: Rubrics for evaluation of self-study

\begin{tabular}{|c|c|c|}
\hline \multirow{6}{*}{$\begin{array}{l}\text { Parameters } \\
\text { for evaluation } \\
\text { and marks } \\
\text { allotted } \\
(20 \mathrm{M})\end{array}$} & Topic selection & $2 \mathrm{M}$ \\
\hline & $\begin{array}{l}\text { Discussion to arrive at the title of the } \\
\text { paper and content (as a team) }\end{array}$ & $2 \mathrm{M}$ \\
\hline & Paper write-up & $4 \mathrm{M}$ \\
\hline & Originality (Plagiarism) & $4 \mathrm{M}$ \\
\hline & Presentation & $4 \mathrm{M}$ \\
\hline & Publication in conference or journal & $4 \mathrm{M}$ \\
\hline
\end{tabular}

The POs defined by NBA and the POs attained through selfstudy are shown in table II.

Table II-POs attained through self-study

\begin{tabular}{|l|l|l|l|}
\hline $\begin{array}{l}\text { PO } \\
\text { No }\end{array}$ & $\begin{array}{l}\text { POs defined } \\
\text { by NBA }\end{array}$ & $\begin{array}{l}\text { Rubrics used in } \\
\text { Evaluation of Self } \\
\text { Study }\end{array}$ & $\begin{array}{l}\text { POs } \\
\text { addressed }\end{array}$ \\
\hline 1 & Engineering Knowledge & Selection of Topic & $\checkmark$ \\
\hline 2 & Problem Analysis & & X \\
\hline 3 & Design/Development & & X \\
\hline 4 & Conduct Investigations & & X \\
\hline 5 & Modern Tool Usage & & X \\
\hline 6 & The Engineer \& Society & Selection of Topic & $\checkmark$ \\
\hline 7 & Environmental Issues & Selection of Topic & $\checkmark$ \\
\hline 8 & Ethics & Originality & $\checkmark$ \\
\hline 9 & Team Work & Paper write-up & $\checkmark$ \\
\hline 10 & Communication & Presentation & $\checkmark$ \\
\hline 11 & Project Management & & X \\
\hline
\end{tabular}

\begin{tabular}{|l|l|l|l|}
\hline 12 & Life Long Learning & $\begin{array}{l}\text { Publication in } \\
\text { conference or } \\
\text { journal }\end{array}$ & $\checkmark$ \\
\hline
\end{tabular}

Normally, in any course, it is difficult to attain higher Program Outcomes (POs). This type of assessment helped to attain higher POs such as PO6, PO7, PO8, PO9, PO10 and PO12 [6].

The PO attainment was calculated based on Continuous Internal Evaluation (CIE), Semester End Examination (SEE) and Course End Survey (CES) as shown in Table III. The weightage assigned for CIE, SEE and CES are 80\%, $10 \%$ and $10 \%$ respectively.

Table III: Calculation of PO attainment

\begin{tabular}{|l|l|l|l|l|l|l|l|l|l|l|l|l|}
\hline & PO1 & PO2 & PO3 & PO4 & PO5 & PO6 & PO7 & PO8 & PO9 & $\begin{array}{l}\text { PO } \\
10\end{array}$ & $\begin{array}{l}\text { PO } \\
11\end{array}$ & $\begin{array}{l}\text { PO } \\
12\end{array}$ \\
\hline $\begin{array}{l}\text { CIE } \\
(80 \%)\end{array}$ & 71 & - & - & - & - & 46 & 46 & 46 & 46 & 46 & - & 46 \\
\hline $\begin{array}{l}\text { SEE } \\
(10 \%)\end{array}$ & 98 & - & - & - & - & - & - & - & - & - & - & - \\
\hline $\begin{array}{l}\text { CES } \\
(10 \%)\end{array}$ & 83 & - & - & - & - & 83 & 83 & 83 & 83 & 83 & - & 83 \\
\hline Overall & 75 & - & - & - & - & 45 & 45 & 45 & 45 & 45 & - & 45 \\
\hline
\end{tabular}

The CO-PO attainment consists of three components. The first component is through CIE and this component is given a weightage of $80 \%$.

The second component is through the SEE, and this component is given a weightage of $10 \%$, as we do not have access to statistics of question-wise performance of the students.

The third component is through the Course End Survey (CES), and this component is given $10 \%$ weightage, as this is a self-assessment of skills gained by the student, through a survey. The overall attainment of POs in the course titled "Sustainable Telecommunication Networks" is shown in fig 4 .

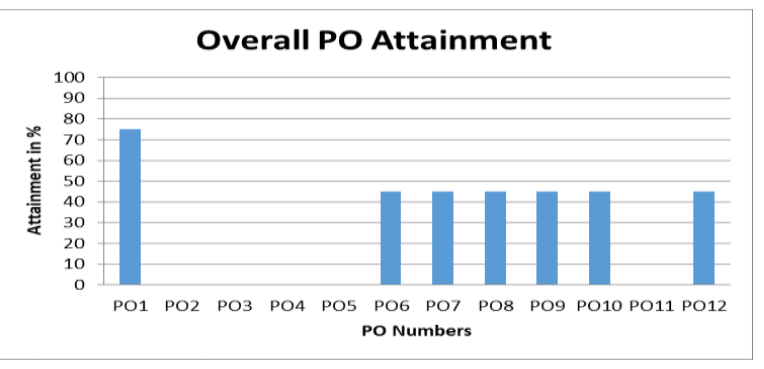

Fig. 4: PO attainment

From fig. 4, it is clear that the attainment of PO6-P10 and PO12 is $45 \%$ due to the fact that the cutoff score for the self-study component was set to $\geq 85 \%$. The $\mathrm{CO} 2$ and $\mathrm{CO} 3$ are mapped to PO1 and CO4 is mapped to PO6-PO10 \& PO12. Table IV shows the attainment calculation of COs.

Table IV: CO attainment Calculation

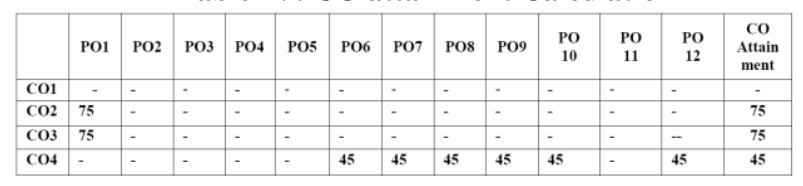


The overall attainment of COs is shown in fig 5.

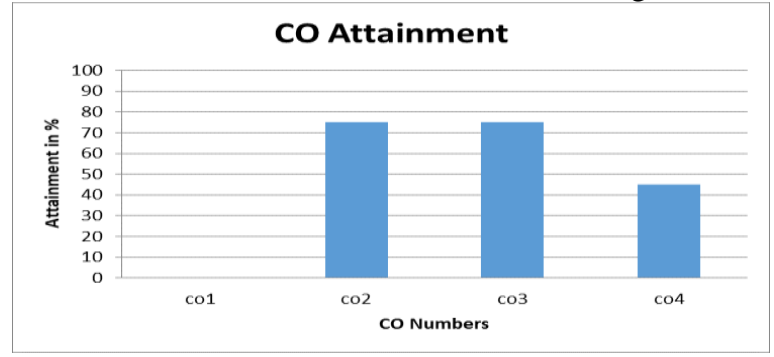

Fig. 5: CO attainment

After successful delivery of the course, the industry expert from Reliance Jio was invited to handle a self-study component for Wireless Communication which is the core course for $7^{\text {th }}$ semester students of ETE branch. The total number of publications in vaious conferences, journals and book chapter for the academic year with the industry expert as the co-author is shown in fig. 6.

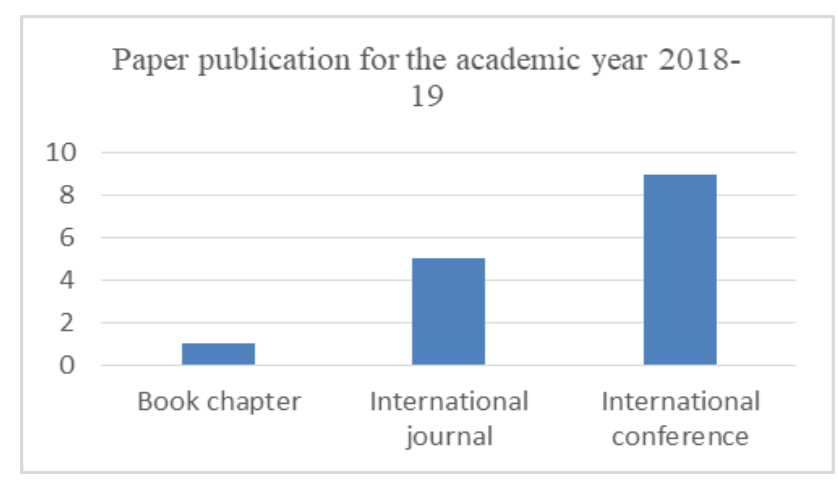

Fig 6: Publication by UG students

From fig. 6 it can be seen that the total number of publications for the academic year 2018-2019 is 15 . Though paper writing is a challenging task, with the help of the industry expert, the students could publish the papers in reputed conferences and journals.

\section{B. Stellapps Technologies}

The MoU with Stellapps Technologies was signed in 2017 to enhance the knowledge and skills in the field of Internet of Things (IoT) in Communication and also to get hands on experience on real time IoT projects. The MoU with this company enabled the students to get internships, work on real time projects and to publish a paper in IEEE Explore. The visit to the industry on a yearly basis helped the students to understand the use of various sensors and their integration in the IoT application for Agriculture and Dairy applications.

The involvement of the experts in evaluating the projects at the institutional level enabled the students to interact with them, exhibit their talents and also to get new ideas to enhance the quality of the projects. The association with this industry has also helped to get the feedback on curriculum design and to introduce new courses as electives.

\section{CB Institute of NW Technologies}

The interaction with the director of $\mathrm{CB}$ Institute of NW technologies (CB Tech) which is a premier training and career development company, specially focused on providing education services in Wired / Wireless networking technologies helped the department to have him as an industry expert for partial delivery of the course on "Computer Communication Networks". This has helped the students to get an overview of the network applications in real life. The department could conduct a faculty development programme and workshops for students to get hands-on training.

\section{Texas Instruments}

An MoU was signed with Texas Instruments to establish a lab titled "BMSCE-Texas Instruments Microcontroller Lab" to have adequate laboratory facilities to supplement students' theoretical knowledge in the area of low power embedded systems, and to gain required body of knowledge in this area. Further, hands-on workshops on "Beagle Board and Android" and "Low Power Microcontrollers-MSP430" were conducted by Texas Instruments in the college campus to provide an in-depth knowledge about the laboratory to students, faculty and research scholars. These workshops have helped faculty and students get an insight into the capabilities of beagle board which in turn helped them carry out research in signal processing and embedded system domain.

The interaction also resulted in the introduction of an elective - "Low Power Microcontroller" - for the $7^{\text {th }}$ semester students of Electronics \& Communication Engineering (ECE), Electrical \& Electronics Engineering (EEE), Electronics \& Telecommunication Engineering (ETE), Electronics \& Instrumentation Engineering (EIE) and Medical Electronics (ML) branches. This has helped students understand the need for low power microcontrollers in day-to-day applications. Students were also inspired to take up industry-oriented projects, which resulted in developing prototype models for societal needs and publishing papers in reputed conferences and journals. The work carried out by undergraduate students of the department of ETE, BMSCE is presented here.

1. Design of Low cost Low Power Motes for Wireless Sensor Networks using MSP430, published in Journal of Information Systems and Communication

2. Designing a Low-cost, Low-power Indigenous Mote using MSP430 and CC2420, Article published in Text book on "MSP430 Microcontroller in Embedded System Projects", Editor: CP Ravikumar, Texas Instruments, ELITE publishing.

3. Minimal Usage of Water Resource for Car Washing using Autonomous Robot", TI India Educators' Conference (TIIEC 2013), April 4th -5th 2013, Bangalore. The presentation and the demo of the projects by the students in the IEEE conference organized by Texas Instruments is shown in fig. 7 . 


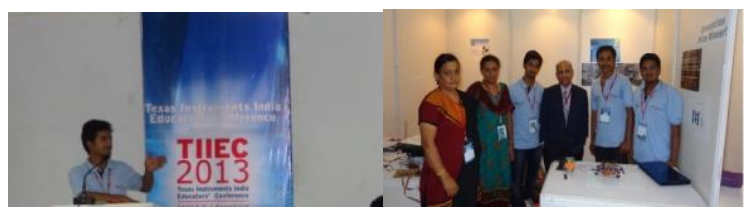

Fig. 7 Presentation and demo by the students

4. "Minimal Usage of Water Resource for Car Washing Using Autonomous Robot", Article published in Text book on "Innovative Electronic System Design Projects", Editor: CP Ravikumar, Texas Instruments, Chitrakara University Press, May 2014

5. MSP430 based Automatic Traffic Violation Detection System using RFID Technology", $7^{\text {th }}$ International Conference on Advanced Computing and Communication Technologies (ICACCT ${ }^{\mathrm{TM}}-2013$ ) in association with Inderscience Publishers, UK, IETE and Technically Co-sponsored by Computer Society Chapter IEEE, Delhi Section

6. Acoustic Perception Based on Real Time Video Acquisition using TMS320DM642", TI News Letter October 2012.

7. ACOUSTIC VISION-Acoustic Perception based on Real Time Video Acquisition for Navigational Assistance", International Journal of Computational Intelligence Techniques

8. Stereo acoustic perception based on Real time video acquisition for Navigational assistance", International Workshop on Signal, Image processing and Multimedia.

Further, alumni who had taken the course provided feedback on how using MSP430 for their projects had helped them significantly, both in their careers as well as in understanding how low power microcontrollers can be useful in day-to-day and industrial applications. As all industries are now looking for devices with lowest power consumption, it was a real career booster to have MSP430 in the resume according to a student who got selected for MS in Aeronautical and Space Systems program (Embedded Systems Major) at ISAE, France with full funding. He credits this achievement to MSP430 microcontrollers in his application statement of purpose (SOP) to the university.

\section{E. ZTE}

An MoU with ZTE India Pvt Ltd was signed to establish a lab titled "3G ZTE Wireless Lab" in the college campus to provide a training facility in the area of Advanced Wireless Communication. A series of workshops were conducted in the college campus for students and faculty on topics such as "Telecom and Technical Management Overview", "Overview of Wireless Communication \& Telecom Market", and "Overview of 3G (WCDMA) \& 4G (LTE) Wireless Communication". These hands-on workshops exposed the students and faculty to the latest trends in wireless communication.

\section{Interaction with industries to promote ethical and} spiritual values

Along with the technical challenges of migrating from the classroom to a fast-paced result-oriented workplace, students often face challenges with time management, interpersonal skills, dealing with stress, and facing the "real-world" more widely. An effective OBE system would also address these issues alongside technical development, to make the workforce more productive and creative. Industry-institute interaction also helps in this regard, as industry experts are able to share practical guidelines and experiences on how they navigated through their professional journey. Some of the initiatives taken by the Department of ETE, BMSCE in this regard are listed below.

A Leader, Artificial Intelligence (AI) Centre of Excellence (CoE) from Intel India Private Ltd delivered a talk on "Campus to Corporate Life" and discussed stress, the factors triggering stress and the methods to overcome stress such as meditation and Yoga practice. He also highlighted the importance of time management in corporate life.

A talk by the director of CREST (Research Institute), inspired the students to explore spirituality, which is within us and would help the students in taking the right decisions and choosing the right path in the present and the future. There was a short session on relaxation techniques that helped students release their stress, tension and increase concentration. The examples of great leaders like Rama, Mahatma Gandhi, Swami Vivekananda, etc. gave students an idea on how to become a leader by living life with discipline and nobility, not restricting oneself, creating a self-identity and earning recognition by working for society and thinking out of the box. The fig. 8 shows the interaction with industry experts on ethical values.

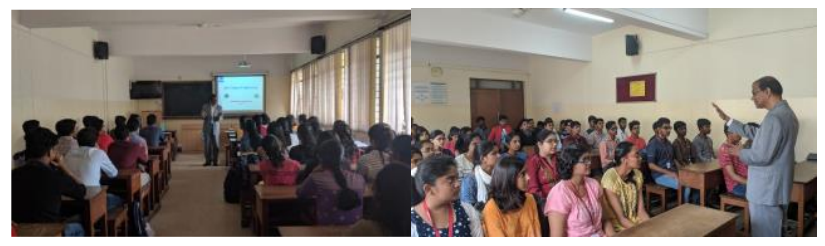

Fig. 8 Interaction with industry experts

The interaction of students with the Director, Saraswati Industries Pvt. Ltd. created awareness on the importance of attitude and response towards choices in shaping their future. He made the students realize that "a real engineer is a student forever".

A talk on heartful relationships by industry expert from Oziel Consulting helped students focus on their relationship status with their family, friends, society etc., and the time they spend for themselves and how they can manage the other relationships. This session gave students a chance to understand others' feelings by visualising themselves in 
their shoes and also gave a deep insight of their inner self. Fig. 9 shows the session with the expert from Oziel Consulting.

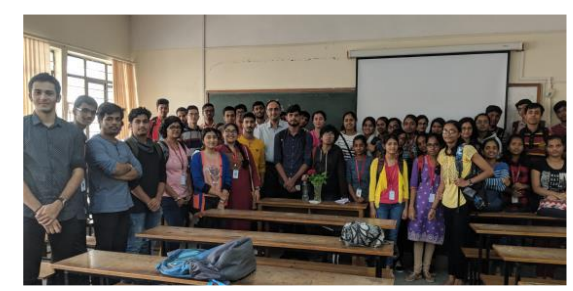

Fig. 9 Session by industry expert from Oziel Consulting

The CEO \& Founder of Welfare Harvesters and Director at MEOH Tech LLP and Heartfulness Meditation trainer gave a brief introduction to self-development. His talk focused on the need and importance of self-development in a student's life. The methods of development are to set out short-term and long-term goals like sprint and marathon. Self-control can be gained through meditation. There were interactive moments between the students and the Speaker, followed by a few minutes of meditation and relaxation of mind and body at the end.

\section{Conclusion}

In this paper, the role of industries for the accomplishment of OBE is presented, using examples of initiatives in the Department of ETE, BMSCE, Bangalore. The proliferation of industries into academic institutes is beneficial for both the parties. The involvement of the expert from Reliance Jio in implementing self-study component of the courses "Sustainable Telecommunication Networks" and "Wireless Communication" helped the students to publish papers in reputed journals and conferences with the industry expert as a co-author. It also helped the department to achieve higher POs such as PO6, PO7, PO8, PO9, PO10 and PO12 as the papers focused on the role of Telecommunication in the sustainable development of community. The institute could produce industry-ready engineers which would help industries to quickly and efficiently utilize their human resources for product development and research. The institute on the other hand is able to provide cutting-edge training to its students and eliminate obsolete modules, thereby hastening the technological progress of society. The MoU also helped the students to get placed in reputed industries. A new course on "Personality Development" was introduced after a series of lectures on ethical and spiritual values.

The academic institutes usually focus on achieving academic excellence and rarely focus on ethical and moral values. The series of lectures held on the above topics have helped the students to become a highly committed individual with moral values and ethics such as integrity, attitude, commitment and behaviour to name a few.

\section{References}

1. R Hegde (2014), doi: 10.1109/MITE.2014.7020281

2. Syed Akram et. al., (2015), Role of Industry to improve Outcome Based Education in Engineering, Journal of Engineering Education Transformations, Special Issue, 358-361.

3. Institute Industry Interaction Council, https://bmsce.ac.in/home/About-IIIC

4. B. S. Nagabhushana and R. Hegde (2015), doi: 10.1109/MITE.2015.7375347.

5. Amith Donald Menezes \& Dr. Prakash Pinto (2016), Role of Industry in Developing the Education System, International Journal of Scientific Research and Modern Education (IJSRME), 1 (1), 385-390.

6. Rajeshwari Hegde et al., (2020) Learning Outcomes of a National Level Project Contest, Journal of Engineering Education Transformations, 34 (2), 5460. 